\begin{tabular}{|c|c|c|c|}
\hline DE & \multirow{3}{*}{$\begin{array}{l}\text { DE GRUYTER } \\
\text { OPEN }\end{array}$} & $\begin{array}{l}\text { HUNGARIAN JOURNAL OF } \\
\text { INDUSTRY AND CHEMISTRY }\end{array}$ & \multirow[t]{3}{*}{ 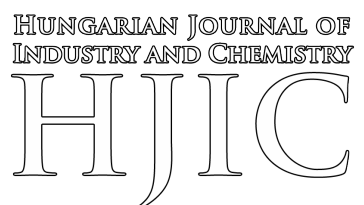 } \\
\hline & & Vol. 43(2) pp. 97-101 (2015) & \\
\hline & & $\begin{array}{l}\text { hjic.mk.uni-pannon.hu } \\
\text { DOI: } 10.1515 / \text { hjic-2015-0016 }\end{array}$ & \\
\hline
\end{tabular}

\title{
COMPARATIVE STUDY OF ADVANCED OXIDATION PROCESSES TO TREAT PETROLEUM WASTEWATER
}

\author{
DheeaA al deen Atallah Aljubourya, ${ }^{1 *}$ Puganeshwary Palaniandy, ${ }^{1}$ Hamidi Bin Abdul Aziz, ${ }^{1}$ \\ AND SHAIK FEROZ \\ ${ }^{1}$ School of Civil Engineering, Universiti Sains Malaysia, Nibong Tebal, Seberang Perai Selatan, Pulau \\ Pinang, 14300, MALAYSIA \\ ${ }^{2}$ Caledonian Center for Creativity \& Innovation $(\mathrm{CCCl})$, Caledonian College of Engineering, P.O.Box \\ 2322, CPO Seeb 111, Muscat, OMAN
}

\begin{abstract}
This study was carried out to compare the performance of different oxidation processes, such as solar photo-Fenton reaction, solar photocatalysis by $\mathrm{TiO}_{2}$, and the combination of the two for the treatment of petroleum wastewater from Sohar Oil Refinery by a central composite design with response surface methodology. The degradation efficiency was evaluated in terms of chemical oxygen demand (COD) and total organic carbon (TOC) reductions. Solar photocatalysis by the $\mathrm{TiO}_{2} /$ Fenton method improved the performance of the photocatalyst at neutral $\mathrm{pH}$ for petroleum wastewater without the need to adjust the $\mathrm{pH}$ during this treatment. Under acidic conditions, the solar photo-Fenton process is more efficient than solar $\mathrm{TiO}_{2}$ photocatalysis while it is less efficient under alkaline conditions. The $\mathrm{TiO}_{2}$ dosage and $\mathrm{pH}$ are the two main factors that improved the TOC and COD reductions in the solar photocatalysis using combined $\mathrm{TiO}_{2} /$ Fenton and the solar $\mathrm{TiO}_{2}$ photocatalysis processes while the $\mathrm{pH}$ and $\mathrm{H}_{2} \mathrm{O}_{2}$ concentration are the two key factors that affect the solar photo-Fenton process.
\end{abstract}

Keywords: solar photo-Fenton process, solar photocatalysis by $\mathrm{TiO}_{2}$, petroleum wastewater, chemical oxygen demand, total organic carbon

\section{Introduction}

A major problem facing industrialised nations is contamination of the environment by hazardous chemicals. A wide range of pollutants have been detected in petroleum wastewater at Sohar Oil Refinery (SOR). Therefore, the elimination of these chemicals from petroleum wastewater is presently one of the most important aspects of pollution control in Oman.

Advanced oxidation processes (AOPs) have the capability of rapid degradation of recalcitrant pollutants in aquatic environments. Remediation of hazardous substances is linked to the hydroxyl radical since it has the potential to degrade organic pollutants [1]. The advantages of AOPs are that these processes can occur at very low concentrations and do not form environmentally hazardous byproducts [2]. During the solar photocatalysis by $\mathrm{TiO}_{2}$, upon exposure to sunlight an electron hole is created in the valence band of $\mathrm{TiO}_{2}$ and concomitantly an electron is injected into the conduction band in response to light absorption. This electron hole causes the oxidation of hydroxyl anions and produces the hydroxyl radicals at the $\mathrm{TiO}_{2}$ surface. During the photo-Fenton process the hydroxyl radicals are formed from the reaction of $\mathrm{Fe}^{2+}$ with $\mathrm{H}_{2} \mathrm{O}_{2}$ under

*Correspondence: msc.dheeaa@yahoo.com sunlight irradiation. In the treatment of nonbiodegradable and toxic compounds, the photocatalytic processes have shown promising results [3].

Previous studies have reported the enhanced oxidation of contaminants by $\mathrm{TiO}_{2}$ photocatalysis in the presence of Fenton reactivity. Kim et al. [4] reported that the combination of $\mathrm{TiO}_{2}$ photocatalysis and the Fenton-like reaction synergistically increased the degradation of organic compounds at around neutral $\mathrm{pH}$ (6.5-7.5) by the increased production of reactive oxidants and their improved reactivity. However, it has not been clearly addressed whether the integration of the $\mathrm{UV} / \mathrm{TiO}_{2}$ and $\mathrm{Fe}^{2+} / \mathrm{H}_{2} \mathrm{O}_{2}$ systems exhibits synergistic results with respect to the degradation of contaminants. Little data are available on the role of $\mathrm{Fe}^{2+}$ ions in the $\mathrm{UV} / \mathrm{Fe}^{2+} / \mathrm{TiO}_{2}$ system at neutral $\mathrm{pH}$, where the $\mathrm{Fe}^{2+} / \mathrm{H}_{2} \mathrm{O}_{2}$ or $\mathrm{UV} / \mathrm{Fe}^{2+} / \mathrm{H}_{2} \mathrm{O}_{2}$ system alone is not effective for oxidant production and pollutant oxidation due to the low aqueous iron solubility and $\mathrm{H}_{2} \mathrm{O}_{2}$ decomposition via a non-radical mechanism without hydroxyl radical generation [1,4,5]. Zarei et al. [6] showed that the removal efficiency of phenol was $69 \%$ after $150 \mathrm{~min}$ using photoelectro-Fenton (PEF)/ $\mathrm{Mn}^{2+} / \mathrm{TiO}_{2}$ nanoparticles for the removal of phenol from aqueous solutions. Nogueira [7] showed that the role of $\mathrm{Fe}^{2+}$ ions and $\mathrm{H}_{2} \mathrm{O}_{2}$ are much more important than that of $\mathrm{TiO}_{2}$ in the photodegradation of both 4-chloro-phenol (4CP) and dichloro-acetic acid (DCA) under solar irradiation [7]. 
Table 1. Overview of research done in the area of $\mathrm{Fenton} / \mathrm{TiO}_{2}$ processes in recent years.

\begin{tabular}{|c|c|c|c|c|}
\hline No. & Wastewater & method & material removed & Ref. \\
\hline 1 & aqueous imidacloprid & $\begin{array}{l}\text { photocatalysis by } \mathrm{TiO}_{2} \\
\text { photo-Fenton }\end{array}$ & imidacloprid & {$[1]$} \\
\hline 2 & Milli-Q water & $\mathrm{TiO}_{2} /$ Fenton-like/solar & 2,4-dinitrophenyl hydrazine (DNPH) & [4] \\
\hline 3 & aqueous solutions & $\mathrm{TiO}_{2} /$ photoelectro-Fenton/ $/ \mathrm{Mn}^{2+} / \mathrm{UV}$ & phenol & [6] \\
\hline 4 & aqueous media & $\mathrm{TiO}_{2} /$ Fenton-like/solar & $\begin{array}{l}\text { 4-chloro-phenol (4CP) and dichloro- } \\
\text { acetic acid (DCA) }\end{array}$ & [7] \\
\hline 5 & oil-water emulsions & $\begin{array}{l}\mathrm{TiO}_{2} / \mathrm{H}_{2} \mathrm{O}_{2} / \mathrm{Fe}^{2+} / \mathrm{UV} \\
\mathrm{TiO}_{2} / \mathrm{H}_{2} \mathrm{O}_{2} / \mathrm{Fe}^{2+} / \mathrm{UV} / \text { air } \\
\mathrm{ZnO} / \mathrm{H}_{2} \mathrm{O}_{2} / \mathrm{Fe}^{2+} / \mathrm{UV}\end{array}$ & $\begin{array}{l}\text { organics measured by reduction in } \\
\text { COD value }\end{array}$ & [9] \\
\hline 6 & dye polluted water & $\begin{array}{l}\mathrm{TiO}_{2} / \mathrm{H}_{2} \mathrm{O}_{2} / \mathrm{Fe}^{2+} / \mathrm{UV} \\
\mathrm{TiO}_{2} / \mathrm{H}_{2} \mathrm{O}_{2} / \mathrm{Fe}^{2+} / \text { solar }\end{array}$ & azo dye basic blue 4 & {$[11]$} \\
\hline 7 & petroleum wastewater & $\begin{array}{l}\mathrm{TiO}_{2} / \mathrm{H}_{2} \mathrm{O}_{2} / \mathrm{Fe}^{2+} / \text { solar } \\
\text { solar photocatalysis by } \mathrm{TiO}_{2} \\
\text { solar photo-Fenton }\end{array}$ & $\begin{array}{l}\text { organics measured by reduction in } \\
\text { COD and TOC values }\end{array}$ & $\begin{array}{l}\text { This } \\
\text { study }\end{array}$ \\
\hline
\end{tabular}

Table 2. Characteristics of petroleum wastewater from Sohar Oil Refinery (SOR).

\begin{tabular}{ccccc}
\hline parameters & units & $\begin{array}{c}\text { ranges of concentration in } \\
\text { petroleum wastewater }\end{array}$ & $\begin{array}{c}\text { average } \\
\text { concentration }\end{array}$ & $\begin{array}{c}\text { standard } \\
\text { discharge limit }\end{array}$ \\
\hline $\mathrm{pH}$ & - & $6-8$ & 7 & $6-9$ \\
Conductivity & $\mu \mathrm{S} \mathrm{cm}^{-1}$ & $2600-3950$ & 3275 & $2000-2700$ \\
TDS & $\operatorname{ppm}\left(\mathrm{mg} \mathrm{dm}^{-3}\right)$ & $1200-1500$ & 1350 & $1500-2000$ \\
TOC & $\mathrm{ppm}\left(\mathrm{mg} \mathrm{dm}^{-3}\right)$ & $220-265$ & 243 & $50-75$ \\
COD & $\mathrm{ppm}\left(\mathrm{mg} \mathrm{dm}^{-3}\right)$ & $550-1600$ & 1075 & $150-200$ \\
\hline
\end{tabular}

The aims of the given study are as follows: (i) comparison of the homogenous (solar photo-Fenton) and heterogeneous photocatalytic systems (solar photocatalysis by $\mathrm{TiO}_{2}$ and solar photocatalysis using combined $\mathrm{TiO}_{2} /$ Fenton processes) by central composite design (CCD) with response surface methodology (RSM) on the basis of their performances with regard to the chemical oxygen demand (COD) and total organic carbon (TOC) in petroleum wastewater and (ii) assessment of treatment efficiencies and the main factors with regard to these methods by CCD and RSM.

To our knowledge there are no reports in the literature of a similar comparison by a central composite design (CCD) with response surface methodology (RSM) applied to the homogeneous and heterogeneous photocatalytic systems for treatment of petroleum wastewater as shown in Table 1.

\section{Materials and Methods}

\subsection{Wastewater Characterisation}

The physicochemical characteristics of the petroleum wastewater from SOR are summarised in Table 2. Samples of the petroleum wastewater were collected on different days. Samples were transferred to the laboratory and stored in a refrigerator at $4{ }^{\circ} \mathrm{C}$ until use. Samples were characterised before the analysis for their chemical and physical properties. The petroleum wastewater was characterised by the quantification of $\mathrm{pH}$ and chemical oxygen demand (COD) according to the Standard Methods for the Examination of Wastewater methodology [12].

\subsection{Materials}

The catalyst used was $\mathrm{TiO}_{2}$ Aeroxide P-25 manufactured by Evonik Industries Co., Germany. Hydrogen peroxide $\left(\mathrm{H}_{2} \mathrm{O}_{2}\right)\left(35 \% \mathrm{dm}^{3} \mathrm{dm}^{-3}\right)$ and iron sulphate hydrate $\left(\mathrm{FeSO}_{4} \cdot \mathrm{xH}_{2} \mathrm{O}\right)$ were supplied by EMPROVE Exp. (USA). Sulphuric acid and sodium hydroxide were used to set the desired $\mathrm{pH}$ values.

\subsection{Analytical Procedures}

A Shimadzu TOC analyser (LCSH/CSN) was used to measure the total organic content (TOC). Chemical oxygen demand (COD) was measured by a COD photometer (manufactured by CHEMetrics). The $\mathrm{pH}$ levels were monitored by using a digital $\mathrm{pH}$ meter. TOC and COD were determined before and after treatment. Before each analysis, samples were filtered by using a $0.22 \mu \mathrm{m}$ Millipore Durapore membrane (40 ashless, diameter $150 \mathrm{~mm}$ ) filter paper.

\subsection{Experimental Procedure}

The solar photocatalytic equipment used is shown schematically in Fig.l consisting of a stirred glass recirculation tank $\left(1.5 \mathrm{dm}^{3}\right)$. The tubular solar reactor contained four tubes $50 \mathrm{~cm}$ in length $\times 2 \mathrm{~cm}$ in inner diameter $\times 0.1 \mathrm{~cm}$ in thickness. The solution was recirculated through the reactor at a flow rate of $1.5 \mathrm{dm}^{3}$ $\min ^{-1}$ using a peristaltic pump. Natural sunlight was used as a light source. The added materials and their concentrations such as $\mathrm{TiO}_{2}, \mathrm{H}_{2} \mathrm{O}_{2}$, and $\mathrm{Fe}^{2+}$ were varied according to a central composite design (CCD) with response surface methodology (RSM) to determine the COD and TOC removal efficiencies under the optimum operational conditions. 


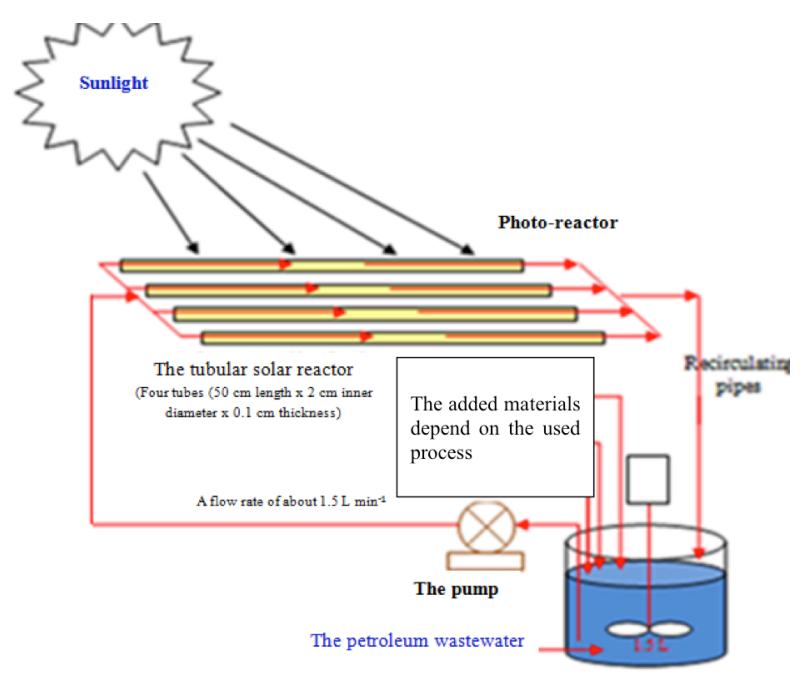

Figure 1. Schematic view of the experimental setup for solar photo-Fenton, solar $\mathrm{TiO}_{2}$ photocatalysis and solar photocatalysis using combined $\mathrm{TiO}_{2} /$ Fenton processes.

\section{Results and Analysis}

\subsection{Effect of $\mathrm{pH}$}

There are two types of Advanced Oxidation Processes (AOPs) depending on the reaction medium: a homogeneous process such as the solar photo-Fenton process, a heterogeneous process such as solar $\mathrm{TiO}_{2}$ photocatalysis, and their combined processes. According to previous results [13], the solar photoFenton process is more efficient for petroleum wastewater treatment than solar $\mathrm{TiO}_{2}$ photocatalysis under acidic conditions.

By comparing solar photocatalysis using combined $\mathrm{TiO}_{2} /$ Fenton processes with the solar photo-Fenton process under the same $\mathrm{pH}$ values, the TOC and COD removal efficiencies improved from $16 \%$ to $23 \%$ and from $27 \%$ to $38 \%$, respectively at $\mathrm{pH} 7$ as shown in Table 3. This enhancement is attributed to increased hydroxyl radical $(\bullet \mathrm{OH})$ production by the presence of $\mathrm{TiO}_{2}$. As shown in Fig.2, solar photocatalysis using combined $\mathrm{TiO}_{2} /$ Fenton processes improves performance at neutral $\mathrm{pH}$ for petroleum wastewater. Therefore, there is no need to adjust the $\mathrm{pH}$ during this treatment.

By comparing these results with previous studies, the results of this work are in agreement with some studies. Ardhendu et al. [2] reported that the greatest TOC reduction took place under photo-Fenton process (PFP). It was found to be more efficient than $\mathrm{UV} / \mathrm{TiO}_{2}$ photocatalysis (UVPC) under acidic conditions. Gbandi et al. [3] found that photocatalysis of $\mathrm{TiO}_{2}$ was independent of the $\mathrm{pH}$ of the solution, while under Fenton photocatalysis, the degradation rate of Orange II increases as the $\mathrm{pH}$ decreases. Duran et al. [8] found that the $\mathrm{TiO}_{2}$ concentration and $\mathrm{pH}$ were the main factors for the $\mathrm{TiO}_{2} /$ Fenton/sunlight method for the degradation of the "blue 4" dye. Kim et al. [4] showed that the synergistic removal of benzoic acid by the $\mathrm{UV} / \mathrm{TiO}_{2} / \mathrm{Fe}^{3+} / \mathrm{H}_{2} \mathrm{O}_{2}$ system was very efficient between
Table 3. Comparing the removal efficiencies (\%) for three degradation processes expressed by TOC and COD under acidic $\mathrm{pH}$ range between 5.5 and 7 of petroleum wastewater.

$\begin{array}{ccccc}\begin{array}{c}\text { Removal } \\ (\%)\end{array} & \mathrm{pH} & \begin{array}{c}\mathrm{TiO}_{2} / \\ \text { solar }^{\mathrm{a}}\end{array} & \begin{array}{c}\text { Fenton/ } \\ \text { solar }^{\mathrm{b}}\end{array} & \begin{array}{c}\mathrm{TiO}_{2} / \text { Fenton/ } \\ \text { solar }^{\mathrm{c}}\end{array} \\ \text { TOC } & 5.5 & 9 & 17 & 26 \\ & 7.0 & 15 & 16 & 23 \\ \text { COD } & 5.5 & 6 & 39 & 61 \\ & 7.0 & 24 & 27 & 38\end{array}$

experimental conditions: ${ }^{\mathrm{a}} 1 \mathrm{~g} \mathrm{dm}^{-3} \mathrm{TiO}_{2}$ and $180 \mathrm{~min}(\mathrm{RT})$; ${ }^{\mathrm{b}} 1 \mathrm{~g} \mathrm{dm}^{-3} \mathrm{H}_{2} \mathrm{O}_{2}, 0.04 \mathrm{~g} \mathrm{dm}^{-3} \mathrm{Fe}^{2+}$ and $180 \mathrm{~min}(\mathrm{RT}) ;{ }^{\mathrm{c}} 1 \mathrm{~g} \mathrm{dm}^{-3}$ $\mathrm{TiO}_{2}, 1 \mathrm{~g} \mathrm{dm}^{-3} \mathrm{H}_{2} \mathrm{O}_{2}, 0.02 \mathrm{~g} \mathrm{dm}^{-3} \mathrm{Fe}^{2+}$ and $180 \mathrm{~min}$ (RT).
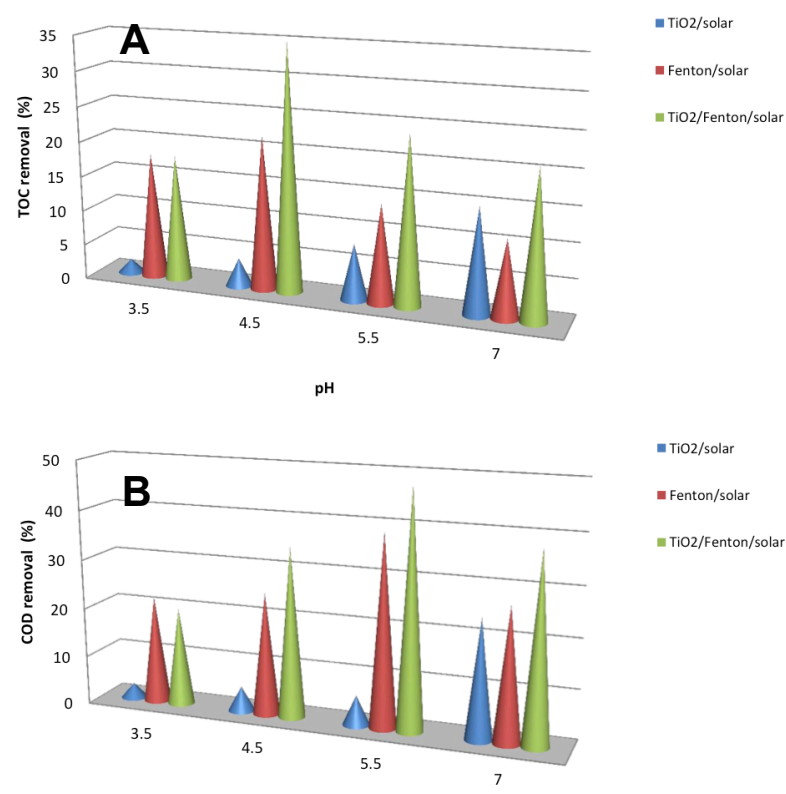

- $-T i 02 /$ solar

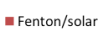

- Tio2/Fenton/solar

$\mathrm{pH}$

Figure 2. Comparison of the three degradation processess of TOC (A) and COD (B) under different $\mathrm{pH}$ values.

the $\mathrm{pH}$ values of 4 and 7 . But, at higher $\mathrm{pH}$ values ( $\mathrm{pH}>7$ ), the addition of $\mathrm{Fe}^{3+}$ and $\mathrm{H}_{2} \mathrm{O}_{2}$ to the $\mathrm{UV} / \mathrm{TiO}_{2}$ system caused negative effects. However, Tony et al. [9] reported that the neutral $\mathrm{pH}$ of the oil-water solution was the optimum $\mathrm{pH}$ value for the degradation of COD by the Fenton/TiO $/$ UV system.

\subsection{Effect of Fenton Reagent and $\mathrm{TiO}_{2}$ Concentration}

The degradation of organic matter monitored by TOC and COD for solar $\mathrm{TiO}_{2}$ photocatalysis is significantly improved by using a Fenton reagent in combination with solar photocatalysis as shown in Fig.2 for the $\mathrm{TiO}_{2} /$ Fenton system. The excess iron has a negative effect because it reacts with hydroxyl radicals reducing the degradation rate of the pollutant [6]. Also, the excess amount of hydrogen peroxide can cause the auto decomposition of $\mathrm{H}_{2} \mathrm{O}_{2}$ to oxygen and water, and the recombination of hydroxyl radicals. Therefore, decreasing the concentration of hydroxyl radicals and 

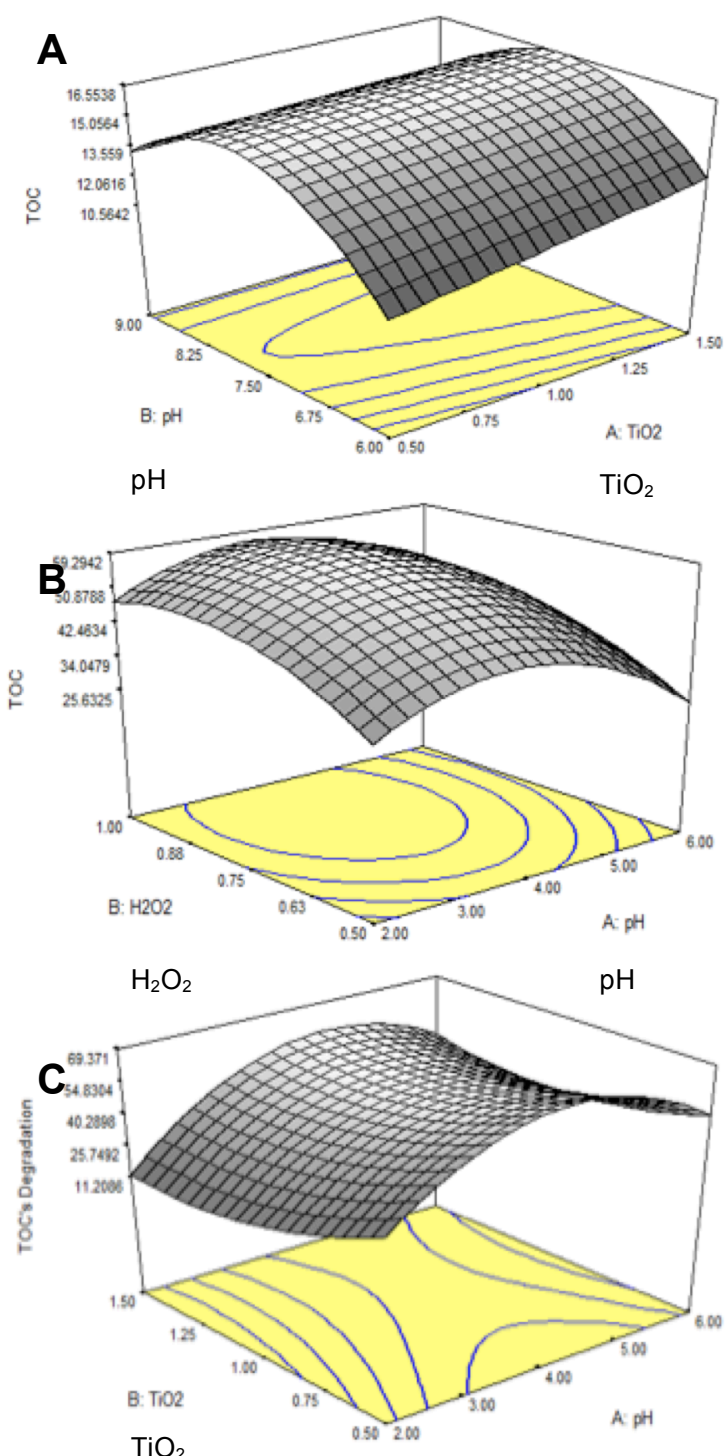

Figure ग. Kesponse surface models for TOC $\mathrm{pH}$ val efficiencies for (A) solar photocatalysis by $\mathrm{I}^{1} \mathrm{U}_{2}$ (B) solar photo-Fenton catalysis (C) solar photocatalysis by $\mathrm{TiO}_{2} /$ Fenton.

reagents reduces efficiency [9]. The degradation rate measured by COD and TOC increases as the $\mathrm{TiO}_{2}$ concentration increases up to the optimum $\mathrm{TiO}_{2}$ dosage in solar $\mathrm{TiO}_{2}$ photocatalysis and solar photocatalysis using combined $\mathrm{TiO}_{2} /$ Fenton processes, which were $1 \mathrm{~g}$ $\mathrm{dm}^{-3}$ and $0.66 \mathrm{~g} \mathrm{dm}^{-3}$, respectively. However, $\mathrm{TiO}_{2}$ dosages greater than the maximum value have a negative effect on these processes since the excess $\mathrm{TiO}_{2}$ particles increase the turbidity of the solution that decreases the penetration of light into the solution resulting in a reduction in production of hydroxyl radicals $(\bullet \mathrm{OH})$ at the $\mathrm{TiO}_{2}$ surface [10].

\subsection{Treatment Efficiency}

To assess the interactive relationships between the independent variables and the responses of certain
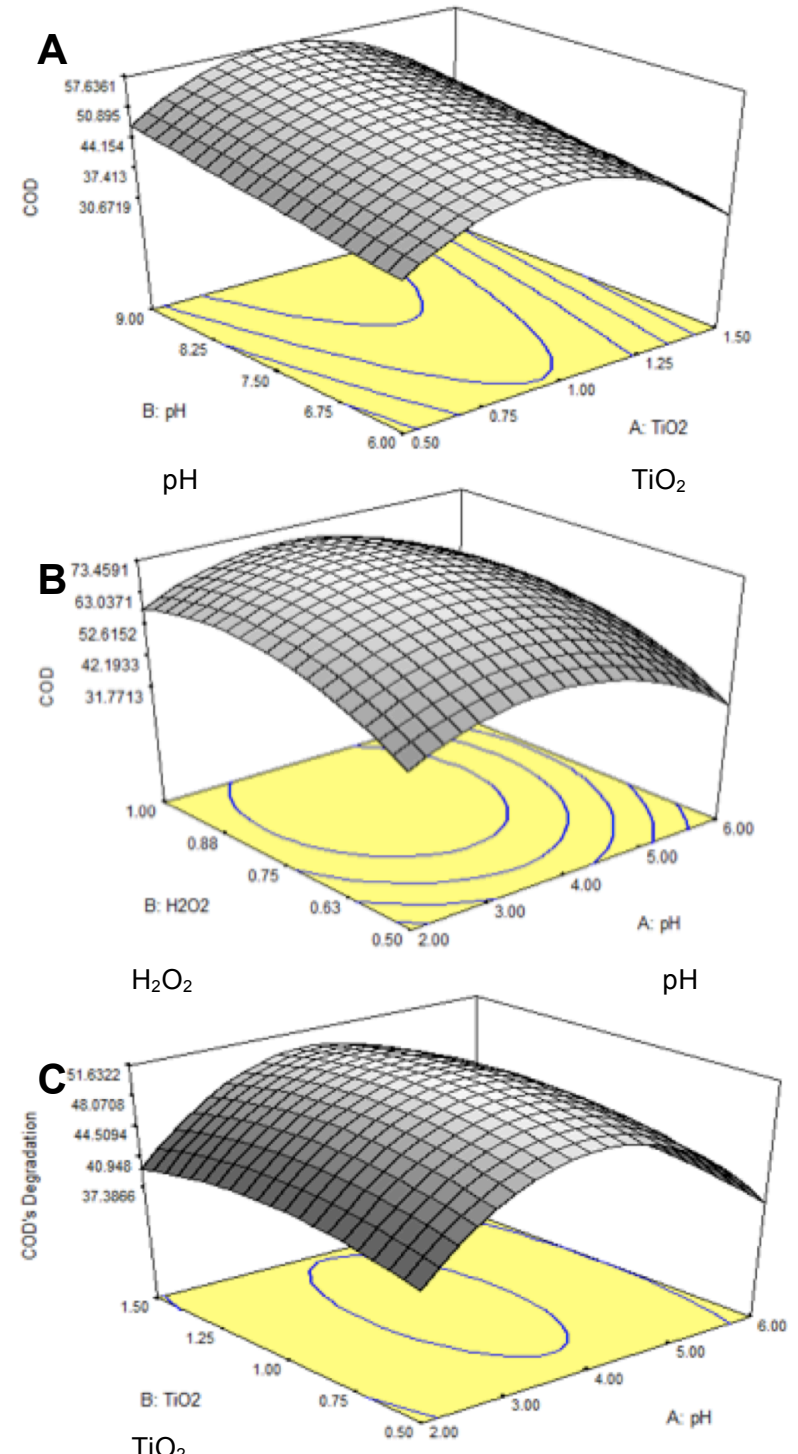

Figure 4. Kesponse surface models for COD pH removal efficiencies for (A) solar photocatalysis by $\mathrm{TiO}_{2}$ (B) solar photo-Fenton catalysis (C) solar photocatalysis by $\mathrm{TiO}_{2} /$ Fenton.

models, 3D surface response plots were created by Design Expert 6.0.7. As shown in Figs.3 and 4, the $\mathrm{TiO}_{2}$ dosage and $\mathrm{pH}$ were the two main factors that improved the TOC and COD values after removal under solar photocatalysis using the combined $\mathrm{TiO}_{2} /$ Fenton and solar $\mathrm{TiO}_{2}$ photocatalysis processes, while the $\mathrm{pH}$ and $\mathrm{H}_{2} \mathrm{O}_{2}$ concentration were the two main factors in the solar photo-Fenton method. The greater removal rates from TOC and COD values under acidic conditions for solar photocatalysis using the combined $\mathrm{TiO}_{2} /$ Fenton and solar photo-Fenton methods were achieved with $\mathrm{pH}$ values of 3.6 and 4.2, respectively. However, they were under alkaline conditions $\left(\mathrm{pH}\right.$ 8) for solar $\mathrm{TiO}_{2}$ photocatalysis. The Fenton ratio and $\mathrm{Fe}^{2+}$ concentration were the essential variables for solar photocatalysis using the combined $\mathrm{TiO}_{2} /$ Fenton and solar photo-Fenton methods, respectively. 


\section{Conclusion}

The given study evaluated the performance of advanced oxidation processes for the treatment of petroleum wastewater by a central composite design with response surface methodology. These processes include solar photo-Fenton catalysis, solar $\mathrm{TiO}_{2}$ photocatalysis, and solar photocatalysis using the combined $\mathrm{TiO}_{2} /$ Fenton processes. The decomposition of organic matter was monitored by chemical oxygen demand and total organic carbon content. We obtained experimental evidence for the superior performance of solar photocatalysis using the combined $\mathrm{TiO}_{2} /$ Fenton methods over using $\mathrm{TiO}_{2}$ only in the case of petroleum wastewater at neutral $\mathrm{pH}$. Under acidic conditions, solar photo-Fenton process was found to be more efficient than solar $\mathrm{TiO}_{2}$ photocatalysis. However, it was less efficient than the solar $\mathrm{TiO}_{2}$ photocatalysis under alkaline conditions. The $\mathrm{TiO}_{2}$ dosage and $\mathrm{pH}$ can be used to improve the TOC and COD values for solar photocatalysis using the combined $\mathrm{TiO}_{2} /$ Fenton processes and solar $\mathrm{TiO}_{2}$ photocatalysis only. The $\mathrm{pH}$ and $\mathrm{H}_{2} \mathrm{O}_{2}$ concentration are the two main factors that influence the efficiency of the solar photo-Fenton process.

\section{REFERENCES}

[1] Giri, A.S.; Golder, A.K.: Fenton, photo-Fenton, $\mathrm{H}_{2} \mathrm{O}_{2}$ photolysis, and $\mathrm{TiO}_{2}$ photocatalysis for dipyrone oxidation: Drug removal, mineralisation, biodegradability, and degradation mechanism, Ind. Eng. Chem. Res., 2014, 53(1), 1351-1358. DOI $10.1021 / \mathrm{ie} 402279 \mathrm{q}$

[2] Durán, A.; Monteagudo, J.M.: Solar photocatalytic degradation of reactive blue 4 using a Fresnel lens, Water Res., 2007, 41(3), 690-698. DOI 10.1016/j.watres.2006.06.042

[3] Djaneye-Boundjou, G.; Amouzou, E.; Kodom, T.; Tchakala, I.; Anodi, K.; Bawa, L.M.: Photocatalytic degradation of orange II using mesoporous $\mathrm{TiO}_{2}$ (P25) and Fenton reactivity, Int . J. Environ. Sci., Manage. \& Eng. Res., 2012, 1(2), 91-96. www.ijesmer.com/web_documents/20121_2_006.pdf

[4] Hermosilla, D.; Cortijo, M.; Huang, C.P.: Optimising the treatment of landfill leachate by conventional Fenton and photo-Fenton processes, Sci. Total Environ., 2009, 407(11), 3473-3481. DOI 10.1016/j.scitotenv.2009.02.009
[5] Kim, H.-E.; Lee, J.; Lee, H.; Lee, C.: Synergistic effects of $\mathrm{TiO}_{2}$ photocatalysis in combination with Fenton-like reactions on oxidation of organic compounds at circumneutral $\mathrm{pH}$, Appl. Catal. B: Environ., 2012, 115, 219-224. DOI 10.1016/j.apcatb.2011.12.027

[6] Lee, H.-S.; Hur, T.; Kim, S.; Kim, J.-H.; Lee, H.-I.: Effects of $\mathrm{pH}$ and surface modification of $\mathrm{TiO}_{2}$ with $\mathrm{SiO}_{\mathrm{X}}$ on the photocatalytic degradation of a pyrimidine derivative, Catal. Today, 2003, 84(1) 173-180. DOI 10.1016/S0920-5861(03)00271-2

[7] Malato, S.; Caceres, J.; Agüera, A.; Mezcua, M.; Hernando, D.; Vial, J.; Fernandez-Alba, A.R.: Degradation of imidacloprid in water by photoFenton and $\mathrm{TiO}_{2}$ photocatalysis at a solar pilot plant: A comparative study, Environ. Sci. Technol., 2001, 35(1), 4359-4366. DOI 10.1021/es000289k

[8] Nogueira, R.F.; Trovó, A.G.; Paterlini, W.C.: Evaluation of the combined solar $\mathrm{TiO}_{2}$ /photoFenton process using multivariate analysis, Water Sci. Technol., 2004, 49(4), 195-200. hwst.iwaponline. com/content/49/4/195

[9] Bouras, P.; Lianos, P.: Synergy effect in the combined photo degradation of an azodye by titanium dioxide photocatalysis and photo-Fenton oxidation, Catal. Lett., 2008, 123, 220-225. link.springer.com/article/10.1007\%2Fs10562-008-9466-9

[10] Tony, M.A.; Zhao, Y.Q.; Purcell, P.J.; El-Sherbiny, M.F.: Evaluating the photocatalytic application of Fenton's reagent augmented with $\mathrm{TiO}_{2}$ and $\mathrm{ZnO}$ for the mineralisation of an oil-water emulsion, $J$. Environ. Sci. Health A, 2009, 44(5), 488-493. DOI 10.1080/10934520902719894

[11]Zarei, M.; Khataee, A.; Fathinia, M.; Seyyednajafi, F.; Ranjbar, H.: Combination of nano photocatalysis with electro-Fenton like process in the removal of phenol from aqueous solution: GC analysis and response surface approach, Int. J. Ind. Chem., 2012, 3(1), 27-28. DOI 10.1186/2228-5547-3-27

[12] Standard Methods for the Examination of Water and Wastewater (American Public Health Association (APHA), 21 th ed., Washington, DC) 2005.

[13] Aljuboury, D.D.A.; Palaniandy, P.; Abdul Aziz, H.B.; Feroz, S.: Treatment of petroleum wastewater using combination of solar photo-two catalyst $\mathrm{TiO}_{2}$ and photo-Fenton process, $J$. Environ. Chem. Engng., 2015, 3(2), 1117-1124 DOI 10.1016/j.jece.2015.04.012 